\title{
ROAD PAVEMENT LONGITUDINAL EVENNESS QUANTIFICATION AS STATIONARY STOCHASTIC PROCESS
}

\author{
Bohuš LEITNER ${ }^{1^{*}}$, Martin DECKÝ ${ }^{2}$, Matúš KOVÁČ 3 \\ ${ }^{1}$ Faculty of Security Engineering, University of Žilina, Slovakia \\ ${ }^{2,3}$ Faculty of Civil Engineering, University of Žilina, Slovakia
}

Received 27 October 2016; revised 13 April 2017, 26 May 2017; accepted 6 July 2017

\begin{abstract}
One of the requirements concerning pavement quality is the evenness of its surface. Pavement unevenness has a random character and has an adverse influence to rolling resistance, tyre-pavement coherence, safety and the driving comfort. Knowledge of "longitudinal unevenness" has been long recognized as an important criteria of road performance, not only for safety by causing vehicle vibrations and affecting ride comfort but also as a major factor in pavement deterioration and working conditions of vehicles. The paper presents two original devices for the measurement of pavement longitudinal unevenness designed as a reaction to results and experiences gathered from a few years' research activities, measurements and evaluations of road pavement evenness carried out in the authors' work place (University of Žilina - UNIZA). The first equipment has been designed as a single-wheel trailing vehicle and has been constructed on the Double-mass Measuring Set (DMS) principle and it is referred to as UNIZA single-wheel vehicle JP VSDS. The main reason for designing the device were authors' findings that the reference quarter car model (used for calculation of International Roughness Index - IRI) can provide evaluation, which can be in contradiction with ride safety. This fact is determined by overvaluation of the short wavelengths and undervaluation the longer wavelengths by reference model. The second one is a profiler with very high resolution of surface scanning using mathematical models for unevenness evaluation. The device is referred to as Dynamic Road Scanner (DRS). The reason for designing of this equipment was in the first place insufficient repeatability of transversal unevenness measurements of device used by Slovak Road Administration, but for the purpose of correctness and measurements accuracy verifying were also results of longitudinal unevenness measurements compared. The paper presents results of evaluation by international established dynamic quantifiers of longitudinal unevenness based on measurements performed by these devices on three selected road sections in Slovakia. In the next part of the paper are compared IRI values obtained by mathematical calculations using reference quarter car model "driving" on road section profile measured by geodetic survey with IRI values obtained by conversion of the unevenness degree C (measured by UNIZA single-wheel vehicle JP VSDS) and IRI values measured by profilometer DRS.
\end{abstract}

Keywords: pavement, longitudinal evenness, stationary stochastic process, power spectral density, single-wheel vehicle, dynamic response, acceleration, international roughness index, surface scanning.

\section{Introduction}

Kropáč and Múčka (2009) presented, that the need for a suitable method for characterisation of road unevenness was recognised by the beginning of the twentieth century with the rapid development of motorised road transport. During that time, a measure of unevenness was introduced as the maximal clearance between a lath (straightedge) laid on the road. This simple method is still in use, usually in a mechanised form. In the course of the 1930s, several one-purpose devices were developed, which were based on different geometric descriptions of the road surface. These devices provided various indicators, which were only vaguely comparable with other indicators and were based on different conceptual ideas. Step by step, one-purpose devices gained popularity, which even at that time were based on the system view that it is important to consider some characteristic of the unevenness in conjunction with its effect on the travelling vehicle. Devices of this type usually measured the response of a suitable mass to the unevenness excitation.

The review of commonly used indicators of longitudinal unevenness of roads and airfield runways was provided by Willett et al. (2000); Delanne, Pereira (2001); Praticò

*Corresponding author. E-mail: bohus.leitner@fbi.uniza.sk 
(2004); Kropáć, Múčka (2006); Wilde (2007); Chemistruck et al. (2009) and Múčka (2015). Several road unevenness indicators used in this study (International Roughness Index - IRI, Power Spectral Density - PSD parameters) are included into the standard proposal EN 13036-5:2014, which standardizes various possible characterizations of road profile unevenness.

The IRI was established in 1986 and based on earlier work performed for National Cooperative Highway Research Program - NCHRP (Sayers et al. 1986). IRI is calculated from a measured longitudinal road profile by accumulating the output from a quarter-car model and dividing by the profile length to yield a summary roughness index with units of slope (Sayers 1995). The Pavement Management System (PMS) is a tool for effective dividing of budget for the management of road rehabilitation. The system includes processes for effective maintenance, repairs and renewal of the road surface and structure (Mikolaj et al. 2013). The processes are based on diagnostics of the pavement surface parameters (serviceability level of pavement) and bearing capacity. Ones of the most important input parameters into European PMS are the roughness and longitudinal evenness (Celko et al. 2008; Kotek et al. 2015; Mikolaj et al. 2014). However, results gathered from a few years' research activities carried out in the authors' work place show that critical rank of evaluation of real response to unevenness are wavelengths corresponding with resonant frequency of car sprung mass. The reference model declares lower values of acceleration of the sprung mass as a real car. The values of a real car model are two times more for speed $90 \mathrm{~km} / \mathrm{h}$ and four times more for speed $130 \mathrm{~km} / \mathrm{h}$ (Celko et al. 2009), which is very inconvenient fact in term of ride safety and furthermore in term of subsequent PMS actions planning. All these results also encouraged authors for designing original devices for the measurement of pavement unevenness, with goal make evaluation more objective and with high rate of repeatability.

\section{Analytical description of pavement longitudinal unevenness}

An analytical description of spatial pavement unevenness is very complicated problem. On this account, it is advisable to supply spatial problem by two-dimensional one and to evaluate separately cross and longitudinal unevenness. A problem longitudinal unevenness has been solved for 20 years on our department and next papers were published about it Decký $(1996,1999)$; Celko et al. (2009) and Decký, Kováč (2014). In the most elementary case, a harmonic sinusoidal form in one trail, we can express a longitudinal unevenness in time scale by equation in form:

$$
\begin{aligned}
& h(t)=h_{0} \cdot \sin \left(2 \cdot \pi \cdot \frac{v}{L} \cdot t\right) \equiv \\
& h_{0} \cdot \sin (2 \cdot \pi \cdot f \cdot t) \equiv h_{0} \cdot \sin (\omega \cdot t),
\end{aligned}
$$

where: $h_{0}$ is unevenness amplitude; $L$ is unevenness wave- length; $v$ is wheel velocity; $t$ is time; $f$ is time frequency; $\omega$ is angular circular frequency.

The stochastic variable is represented by discrete values of the measured profile elevations. The harmonic process of longitudinal unevenness is only rare and real pavements have unevenness of various wavelength and amplitude. These processes from the point of view of mathematics statistic can be considered as a random process with Gauss distribution. An important requirement of technical applications is a fulfilment of stationary and ergodic premise. This imposition must be provided by appropriate selection of evaluated road sections, which are homogenous from the point of view of construction and degradation conditions. Every centred stationary random process can be characterized by correlation function or PSD. Correlation function $K_{h}(\lambda)$, for this type of process, is expressed by equations in form:

$$
K_{h}(\lambda)=\lim _{T \rightarrow \infty} \frac{1}{T} \cdot \int_{0}^{T} h(t) \cdot h(t+\lambda) d t,
$$

where: $\lambda$ is time lag.

For our purpose of unevenness assessment, it is more appropriate to use PSD $S_{h}(\omega)$, which we can express from correlation function by means of Wiener-Khinchin equation in form:

$$
S_{h}(\omega)=\frac{2}{\pi} \cdot \int_{0}^{\infty} K_{h}(\lambda) \cdot \cos (\omega \cdot \lambda) d \lambda .
$$

The design of a system pavement assessment from the point of view of longitudinal unevenness was realized for a consideration stationary random process. Stochastic unevenness is computed as a difference between a real and theoretical profile. In our case were identified elevations of longitudinal profile per $0.25 \mathrm{~m}$ on three road sections measured by geodetic survey. For verification was also evaluated a theoretical profile created by superposed harmonic curves. Longitudinal unevenness were subsequently evaluated through PSD and the standardized correlation function, which is calculated according to equation as follows:

$$
\rho_{h}(\lambda)=\frac{K_{h}(\lambda)}{D_{h}}
$$

where: $K_{h}(\lambda)$ is correlation function of stochastic unevenness; $D_{h}$ is a dispersion of stochastic unevenness.

\section{Dynamic quantification of longitudinal unevenness}

There are two different principles for longitudinal unevenness evaluating considering in the article. The one is based on direct measuring of sprung mass acceleration, where the dynamic quantifier is the unevenness degree $C$. The other one is based on contactless measurement of the pavement surface profile, which is used as an input for the Reference Quarter Car Simulation (RQCS), where the dynamic quantifier is the IRI. 
The unevenness degree $\mathrm{C}$ used for evaluation of road sections and verification is expressed from the basic relation (Decký et al. 2004a) in form:

$$
C=\frac{D_{y}}{I \cdot v},
$$

where: $C$ is the unevenness degree; $D_{y}$ is a dispersion of sprung mass acceleration; $I$ is a parameter of dynamic transfer; $v_{i}$ is quasi-constant velocity.

In accordance with results of work (Decký 1996) were used following input parameters for evaluation in term of the construction conditions (to select window of the length $10 \mathrm{~m}$ without overlapping) and from the point of view of ride comfort and safety (to select window of the length $100 \mathrm{~m}$ with overlapping $10 \mathrm{~m}$ ). Figure 1 shows the quarter-car model in the IRI. It includes the major dynamic effects that determine how roughness causes vibrations in a road vehicle.

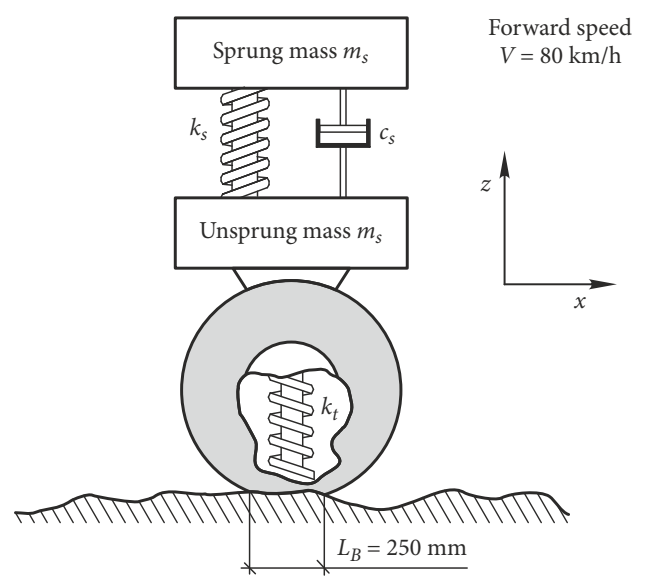

Figure 1. Quarter-car model (Sayers 1995)

The masses, springs, and dampers showed in the Figure 1 are defined by the following parameters such as $c_{s}$ - suspension damping rate; $k_{s}$ - suspension spring rate; $k_{t}$ - tire spring rate; $m_{s}-$ sprung mass (portion of vehicle body mass supported by one wheel); $m_{u}$ - unsprung mass (mass of wheel, tire, and half of axle/suspension). To simplify the equations for mathematical model of the RQCS, the parameters are normalized by the sprung mass $m_{s}$. The following values for the normalized parameters define the Golden Car data set (Sayers 1995):

$$
\begin{aligned}
& c=\frac{c_{s}}{m_{s}}=6.0 ; \\
& k_{1}=\frac{k_{t}}{m_{s}}=653 ; \\
& k_{2}=\frac{k_{s}}{m_{s}}=63.3 ; \\
& \mu=\frac{m_{u}}{m_{s}}=0.15 .
\end{aligned}
$$

The IRI is an accumulation of the simulated motion between the sprung $m_{s}$ and unsprung $m_{u}$ masses in the quarter-car model, normalized by the length $L$, of the profile:

$$
\begin{aligned}
& I R I=\frac{1}{L} \cdot \int_{0}^{L / V}\left|\dot{z}_{s}-\dot{z}_{u}\right| d t \\
& t=\frac{x}{V} .
\end{aligned}
$$

Time influence is indicated with a dot (e.g. $\dot{z}_{s}$ ). Time is related to longitudinal distance $x$ by the simulated derivatives speed $V=80 \mathrm{~km} / \mathrm{h}$ of the vehicle. For the purpose of verification of designed devices reliability was the IRI calculated using developed algorithm IRI-KCS (Decký, Kováč 2014) according to (Sayers 1995) as an arithmetic average of the corrected profile slope $T_{i}$ as follows:

$$
I R I=\frac{1}{N-1} \cdot \sum_{i=2}^{N} T_{i},
$$

where: $T_{i}$ is a difference of sprung and unsprung mass velocities; $N$ is number of discrete profile elevations taking into account.

This is calculated using mathematical model of the RQCS defined mathematically by two second-order differential equations in form:

$$
\begin{aligned}
& \ddot{z}_{s} \cdot m_{s}+C_{s} \cdot\left(\dot{z}_{s}-\dot{z}_{u}\right)+k_{s} \cdot\left(z_{s}-z_{u}\right)=0 ; \\
& \ddot{z}_{s} \cdot m_{s}+m_{u} \cdot \ddot{z}_{u}+k_{t} \cdot z_{u}=k_{t} \cdot y,
\end{aligned}
$$

where: $m_{s}, m_{u}$ is weight of the sprung/unsprung mass; $k_{s}, k_{t}$ is the constant of the linear spring and the tire; $C_{s}$ is coefficient of linear damper; $z_{s}, z_{u}$ is displacement of the sprung/ unsprung mass; $\dot{z}_{s}=\frac{d z_{s}}{d t}, \dot{z}_{u}=\frac{d z_{u}}{d t}$ is vertical velocity of the sprung/unsprung mass; $\ddot{z}_{s}=\frac{d^{2} z_{s}}{d t^{2}}, \ddot{z}_{u}=\frac{d^{2} z_{u}}{d t^{2}}$ is vertical acceleration of the sprung/unsprung mass; $y(t)$ is profile elevation input. However, the model is solved in geometric domain using as an input elevations of the real profile at least per $0.25 \mathrm{~m}$, whereupon must be find a vector of spatial derivations $\mathbf{Z}^{T}(x)_{(i)}=\left(z_{1 i} ; z_{2 i} ; z_{3 i} ; z_{4 i}\right)$.

The values of this vector are calculated as (Sayers 1995):

$$
\begin{aligned}
& \dot{z}_{s, i}=s_{11} \cdot \dot{z}_{s, i-1}+s_{12} \cdot \ddot{z}_{s, i-1}+ \\
& s_{13} \cdot \dot{z}_{u, i-1}+s_{14} \cdot \ddot{z}_{u, i-1}+r_{1} \cdot \dot{y}_{i} ; \\
& \ddot{z}_{s, i}=s_{21} \cdot \dot{z}_{s, i-1}+s_{22} \cdot \ddot{z}_{s, i-1}+ \\
& s_{23} \cdot \dot{z}_{u, i-1}+s_{24} \cdot \ddot{z}_{u, i-1}+r_{2} \cdot \dot{y}_{i} ; \\
& \dot{z}_{u, i}=s_{31} \cdot \dot{z}_{s, i-1}+s_{32} \cdot \ddot{z}_{s, i-1}+ \\
& s_{33} \cdot \dot{z}_{u, i-1}+s_{34} \cdot \ddot{z}_{u, i-1}+r_{3} \cdot \dot{y}_{i} ; \\
& \ddot{z}_{u, i}=s_{41} \cdot \dot{z}_{s, i-1}+s_{42} \cdot \ddot{z}_{s, i-1}+ \\
& s_{43} \cdot \dot{z}_{u, i-1}+s_{44} \cdot \ddot{z}_{u, i-1}+r_{4} \cdot \dot{y}_{i} .
\end{aligned}
$$

The presented system can be expressed in the following matrix form:

$$
\mathbf{Z}(x)_{(i)}=\underline{\mathbf{S}} \cdot \mathbf{Z}(x)_{(i-1)}+\mathbf{R} \cdot \dot{y}_{(i)},
$$

where: $\mathbf{Z}(x)_{(i)}$ is vector of spatial derivations: 


$$
\begin{aligned}
& \mathbf{Z}^{T}(x)_{(i)}=\left(z_{1, i}, z_{2, i}, z_{3, i}, z_{4, i}\right)= \\
& \left(\dot{z}_{s, i}, \ddot{z}_{s, i}, \dot{z}_{u, i}, \ddot{z}_{u, i}\right)= \\
& \left(\frac{d z_{s, i}}{d x}, \frac{d^{2} z_{s, i}}{d x}, \frac{d z_{u, i}}{d x}, \frac{d^{2} z_{u, i}}{d x}\right) ;
\end{aligned}
$$

$\mathbf{S}$ is state transition matrix $(4 \times 4)$; $\mathbf{R}$ is partial response matrix $(1 \times 4) ; \dot{y}_{(i)}$ is slope of the profile input in form:

$$
\dot{y}_{(i)}=\frac{y_{(i-1)}-y_{(i)}}{\Delta} \text { for } i=2,3, \ldots, N \text {, }
$$

where: $\dot{y}_{(i)}$ is smoothed profile slope input (using $y_{(i)}$ elevation of longitudinal profile per $0.25 \mathrm{~m}) ; \Delta$ is measurement interval $(\Delta=0.25 \mathrm{~m})$.

The whole IRI algorithm described in detail can be seen in research by Sayers (1995). These dynamic quantifiers were used for the verification of reliability of designed devices, which could be used for the evaluation of longitudinal unevenness on selected road sections in term of road safety and ride comfort (Cantisani, Loprencipe 2010).

\section{Description of designed devices}

\subsection{UNIZA single-wheel vehicle - JP VSDS}

Our first equipment represents model of a quarter of the passenger vehicle. Its basic parts and dimensions are presented in Figure 2. The measuring car requires a towing vehicle equipped with a special frame in order to stabilise the single-wheel vehicle. A measurement velocity is optional in dependence on the character of a measured road.
For theoretical calculations and practical measurements some basic characteristics had to be determined (Decký 1996):

1) Weights of individual parts:

- weight of a spring and a shock absorber (part 4 in the Figure 1) $-9.5 \mathrm{~kg}$;

- weight of an unsprung mass (parts 1 and 2) - $46.0 \mathrm{~kg}$;

- weight of a sprung mass (parts 3, 5 and 6) - $200.0 \mathrm{~kg}$;

2) Determination of a spring constant:

- by the theoretical calculation - $40.4 \mathrm{kN} / \mathrm{m}$;

- experimentally - $39.2 \mathrm{kN} / \mathrm{m}$;

3) Single-wheel frequency:

- first resonant frequency - by the theoretical calculation $-1.25 \mathrm{~Hz}$;

- experimentally - $1.30 \mathrm{~Hz}$;

- second resonant frequency $-11.80 \mathrm{~Hz}$.

Presented characteristics have been confirmed by experimental measurements. The mechanical model of single-wheel vehicle JP VSDS with detail of accelerometer (Figure 3) was used for measurement. Dynamic response of sprung mass of single-wheel vehicle was indicated by speed control bump - type CZ 8.

The equations of motion for dynamic model of UNIZA single-wheel vehicle according to Figure 3 are as follows:

$$
\begin{aligned}
& m_{1} \cdot \ddot{x}_{1}=k_{1} \cdot\left(x_{0}-x_{1}\right)-f_{21} ; \\
& m_{2} \cdot \ddot{x}_{2}=f_{12} .
\end{aligned}
$$

In the case of small vibrations $\left(\varphi_{1}, \varphi_{2}<5^{\circ}\right)$ the vertical displacements are given by relations $x_{1}=l_{1} \cdot \varphi_{1}$ and $x_{2}=l_{2} \cdot \varphi_{2}$. The force $f_{21}$ in Equation (18) means the force effect of suspension spring and damper onto the mass $m_{1}$
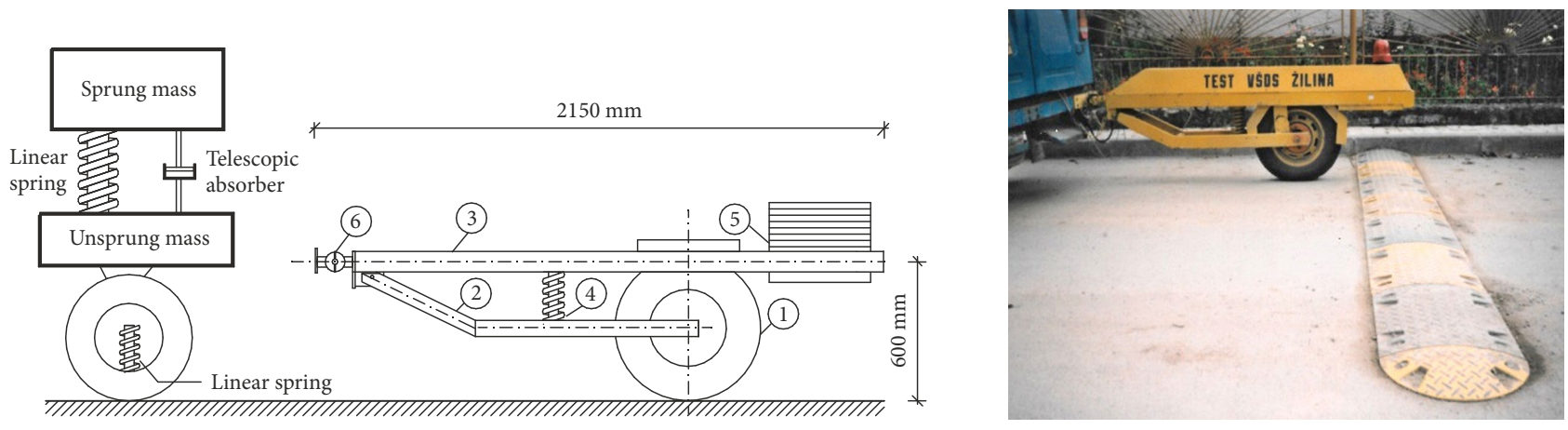

Figure 2. Basic scheme of a UNIZA single-wheel vehicle JP VSDS: 1 - front wheel with a S 120 charge; 2 - bottom frame; 3 - upper frame; 4 - spring and telescopic shock absorber S 120; 5 - balancing load; 6 - cardan joint
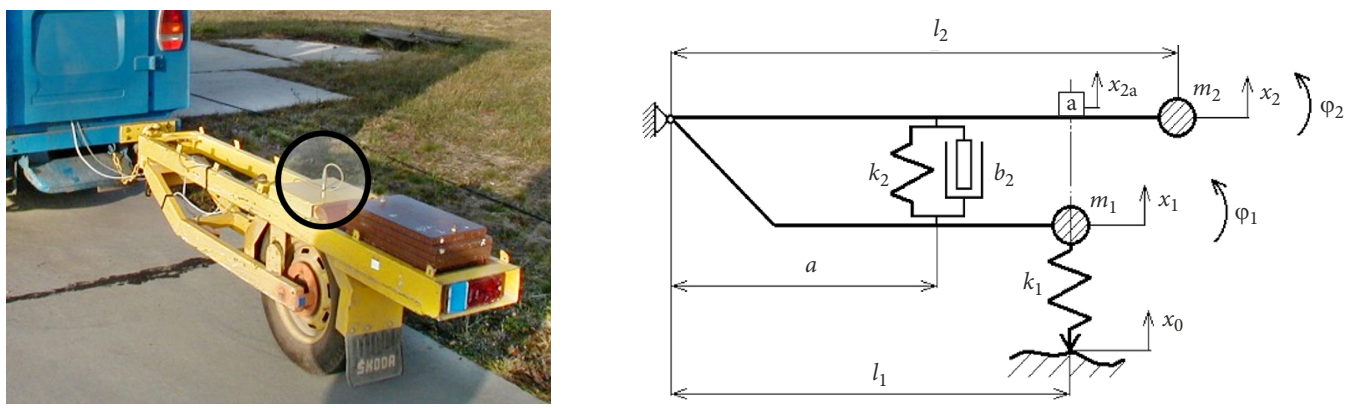

Figure 3. Mechanical scheme of UNIZA single-wheel vehicle JP VSDS (Decký, Kováč 2014) 
in the direct of its vertical axle. On the base of moment equation to the cardan joint, the force $f_{21}$ could be expressed as follows:

$$
\begin{aligned}
& f_{21}=k_{2} \cdot \frac{a^{2}}{l_{1}} \cdot\left(\varphi_{1}-\varphi_{2}\right)+b_{2} \cdot \frac{a^{2}}{l_{1}} \cdot\left(\dot{\varphi}_{1}-\dot{\varphi}_{2}\right)= \\
& k_{2} \cdot \frac{a^{2}}{l_{1}^{2}} \cdot x_{1}-k_{2} \cdot \frac{a^{2}}{l_{1} \cdot l_{2}} \cdot x_{2}+ \\
& b_{2} \cdot \frac{a^{2}}{l_{1}^{2}} \cdot \dot{x}_{1}-b_{2} \cdot \frac{a^{2}}{l_{1} \cdot l_{2}} \cdot \dot{x}_{2} .
\end{aligned}
$$

Similar, the force $f_{12}$ in Equation (19) presents the force reduction effect on the mass $m_{2}$ in direct of its vertical axle:

$$
\begin{aligned}
& f_{12}=k_{2} \cdot \frac{a^{2}}{l_{2}} \cdot\left(\varphi_{1}-\varphi_{2}\right)+b_{2} \cdot \frac{a^{2}}{l_{2}} \cdot\left(\dot{\varphi}_{1}-\dot{\varphi}_{2}\right)= \\
& k_{2} \cdot \frac{a^{2}}{l_{1} \cdot l_{2}} \cdot x_{1}-k_{2} \cdot \frac{a^{2}}{l_{2}^{2}} \cdot x_{2}+ \\
& b_{2} \cdot \frac{a^{2}}{l_{1} \cdot l_{2}} \cdot \dot{x}_{1}-b_{2} \cdot \frac{a^{2}}{l_{2}^{2}} \cdot \dot{x}_{2} .
\end{aligned}
$$

The equations of motion for small vibrations after substitution the Equations (20) and (21) into the Equations (18) and (19) are given by:

$$
\begin{aligned}
& m_{1} \cdot \ddot{x}_{1}+b_{2} \cdot \frac{a^{2}}{l_{1}^{2}} \cdot \dot{x}_{1}-b_{2} \cdot \frac{a^{2}}{l_{1} \cdot l_{2}} \cdot \dot{x}_{2}+ \\
& \left(k_{1}+k_{2} \cdot \frac{a^{2}}{l_{1}^{2}}\right) \cdot x_{1}-k_{2} \cdot \frac{a^{2}}{l_{1} \cdot l_{2}} \cdot x_{2}=k_{1} \cdot x_{0} ; \\
& m_{2} \cdot \ddot{x}_{2}+b_{2} \cdot \frac{a^{2}}{l_{2}^{2}} \cdot \dot{x}_{2}-b_{2} \cdot \frac{a^{2}}{l_{1} \cdot l_{2}} \cdot \dot{x}_{1}+ \\
& k_{2} \cdot \frac{a^{2}}{l_{2}^{2}} \cdot x_{2}-k_{2} \cdot \frac{a^{2}}{l_{1} \cdot l_{2}} \cdot x_{1}=0 .
\end{aligned}
$$

In fact, we do not measure acceleration on the mass $m_{2}$ but on the accelerometer placed on the sprung mass in the distance of tyre vertical axle (Figure 3). From this point of view, it is necessary to rewrite the equations of motion. The vertical displacement (velocity, acceleration) of mass $m_{2}$ can be expressed as a function of geometry and displacement (velocity, acceleration) of accelerometer as follows:

$$
x_{2}=\frac{l_{2}}{l_{1}} \cdot x_{2 a} \rightarrow \dot{x}_{2}=\frac{l_{2}}{l_{1}} \cdot \dot{x}_{2 a} \rightarrow \ddot{x}_{2}=\frac{l_{2}}{l_{1}} \cdot \ddot{x}_{2 a} .
$$

After substitution Equation (23) into Equations (21) and (22) we can rewrite these relations as:

$$
\begin{aligned}
& m_{1} \cdot \ddot{x}_{1}+b_{2} \cdot \frac{a^{2}}{l_{1}^{2}} \cdot\left(\dot{x}_{1}-\dot{x}_{2 a}\right)+ \\
& k_{2} \cdot \frac{a^{2}}{l_{1}^{2}} \cdot\left(x_{1}-x_{2 a}\right)+k_{1} \cdot x_{1}=k_{1} \cdot x_{0} ; \\
& m_{2} \cdot \ddot{x}_{2 \mathrm{a}}+b_{2} \cdot \frac{a^{2}}{l_{2}^{2}} \cdot\left(\dot{x}_{2 \mathrm{a}}-\dot{x}_{1}\right)+ \\
& k_{2} \cdot \frac{a^{2}}{l_{2}^{2}} \cdot\left(x_{2 \mathrm{a}}-x_{1}\right)=0 .
\end{aligned}
$$

The simulated responses were calculated in the developed algorithm IRI-KCS. The measured accelerations were obtained by transducer B 12/200 of the HBM company (by circle in Figure 3) - an inductive type of a scanner of a working frequency $0 \ldots 100 \mathrm{~Hz}$ and sensibility of $0 \ldots 200 \mathrm{~m} / \mathrm{s}^{2}$. The comparison of accelerations measured by UNIZA single-wheel vehicle JP VSDS driving over a speed bump and accelerations calculated by use of model presented on Figure 3 can be seen in Figure 4.

\subsection{Description of dynamic road scanner}

The second designed and developed device uses a noncontact profilometry principle, where the surface of the pavement is measured by eight Gocator profile sensors placed on a measuring beam on the back of the vehicle. An inertial reference is created by algorithm converting accelerations and giving the instant heights of the sensors above the ground. The sensors (laser class $3 \mathrm{~B},<500 \mathrm{~mW}$, $808 \mathrm{~nm}$ ) allow measuring 9600 point in transverse profile of width $4 \mathrm{~m}$. The sampling frequency of sensors $(1 \ldots 5 \mathrm{kHz})$ allows to detect elevation values at intervals of $5 \mathrm{~mm}$. Field of view is in range of $350 \ldots 1000 \mathrm{~mm}$. Degree of protection of all sensors provided against intrusion is IP67. There are two gyroscopes with sensitivity to linear acceleration $0 . \mathrm{g}, 11 \mathrm{~ms}$, and vibration rectification $0.1 \mathrm{~g}^{2} / \mathrm{Hz}$. There are three accelerometers with acceleration $100 \cdot \mathrm{g}$ in all 3 axes without damage, shock $100 \cdot \mathrm{g}$, $11 \mathrm{~ms}$, resolution max. $0.005 \cdot \mathrm{g}$, and bandwidth frequency $150 \mathrm{~Hz}$.

Longitudinal unevenness is evaluated using mathematical model of quarter car simulation according to (Sayers 1995) and unevenness parameters are usually calculated for profiles measured in ruts, between them and on their sides, but can be calculated in every measured

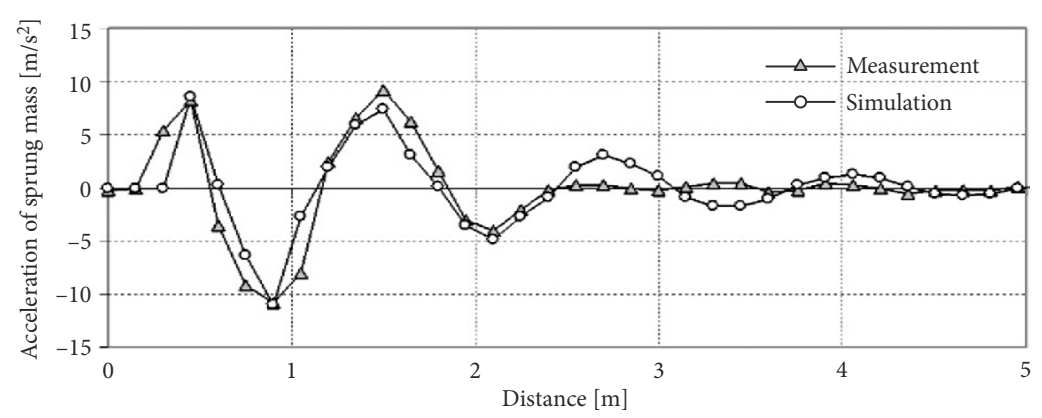

Figure 4. Comparison of measured and simulated dynamic response of sprung mass of JP VSDS initiated by speed control bump (see Figure 2, on the right) 

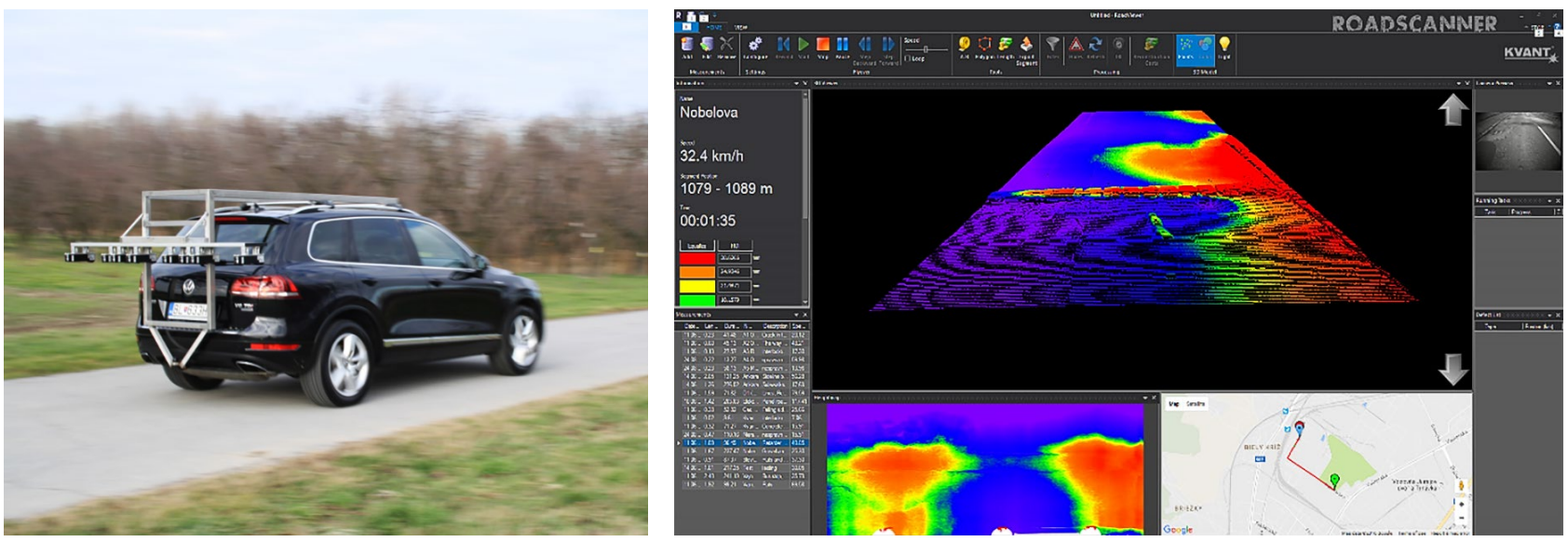

Figure 5. DRS (by KVANT - UNIZA) and workspace of measuring and evaluating software

profile (9600 profiles). All knowledge obtained by comparison of measurement results and simulations results is used for developing and debugging the software created for designed device. The Dynamic Road Scanner (DRS) and the screen shot of workspace of the software used for measurements operation, post-processing and evaluation are shown in the Figure 5.

\section{Verification of longitudinal unevenness evaluation using designed devices}

For the purpose of the verification of reliability of designed devices were identified elevations of the pavement surfaces per $0.25 \mathrm{~m}$ on three road sections (Brodno, Čičmany - Figure 6 and Bridge - Figure 7) measured by geodetic survey. For verification of calculations and simulations was also evaluated a theoretical profile created by superposed harmonic curves (Figure 7). Longitudinal unevenness were subsequently evaluated through the stand- ardized correlation function (Figure 8) and PSD (Figures 9 and 10).

The characteristics of UNIZA single-wheel vehicle JP VSDS, presented in Chapter 3.1, have been confirmed by next experimental measurements. This verification has resulted from premise, that cross unevenness of concrete pavement, at constant distance $6 \mathrm{~m}$, negatively affect evaluated longitudinal unevenness by parameter C. Experimental measurements of a road section I/64 near the Bytča town in the northwest Slovakia have been realised to determine this assumed influence. The results of these measurements can be seen in Table 1 and in Figure 11.

The presented assumption has been almost absolute confirmed for first resonant frequency. We were not able to find out the second self-frequency but we can presume its correctness for a consideration trend of curves in Figure 11.

The parameter $\mathrm{C}$ measured on three road sections by UNIZA single-wheel vehicle JP VSDS were subse-

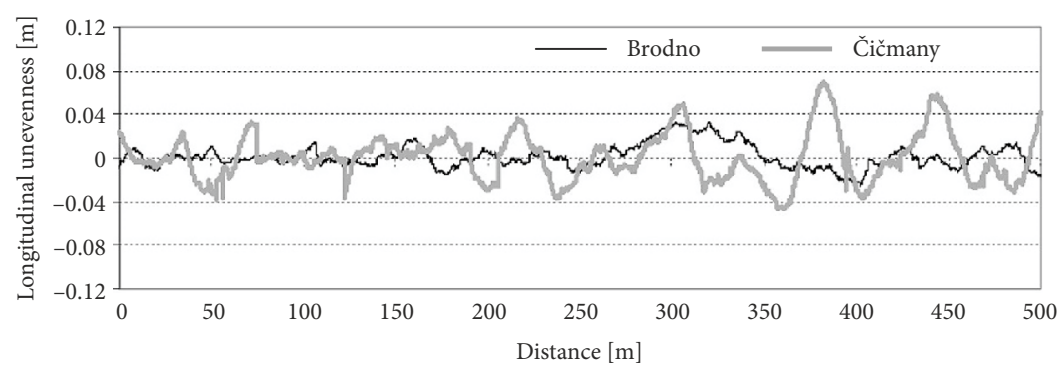

Figure 6. Profile elevations measured by geodetic survey on road sections called Brodno and Čičmany

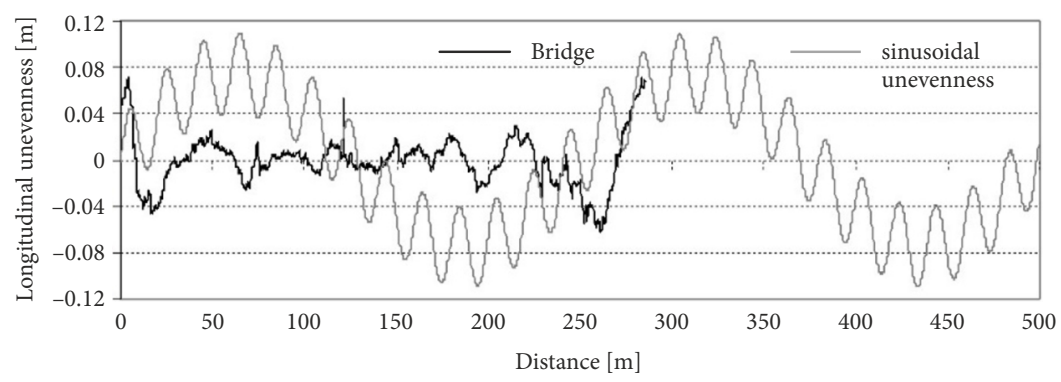

Figure 7. Profile elevations measured by geodetic survey on road section with Bridge and theoretical profile created by superposed harmonic curves 
quently converted to parameter IRI according equations determined by authors (Decký et al. 2004a, 2004b) and compared with results obtained by calculations using presented model. The sample of results of comparison of calculated IRI values obtained by software IRI-KCS using elevations of the profile measured by geodetic survey on selected road section and IRI values obtained by devices DRS and JP VSDS are shown in the Figure 12. Correlation of obtained results is shown in the Figure 13.

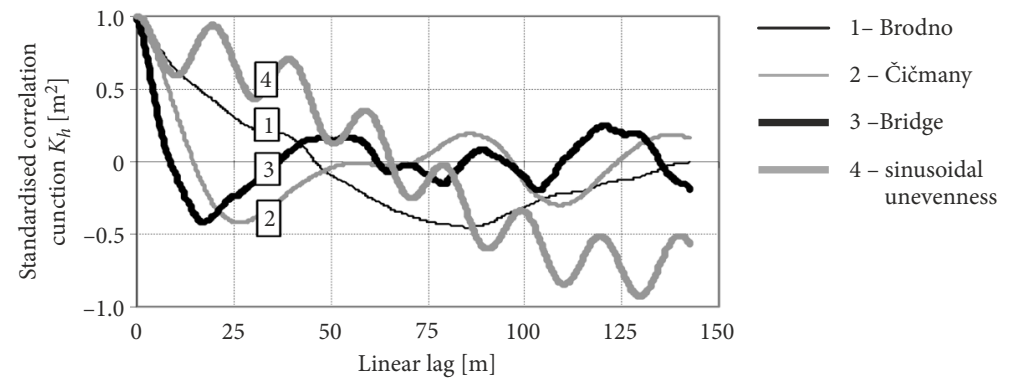

Figure 8. Standardized correlation function of stochastic unevenness of selected road sections and harmonic curve

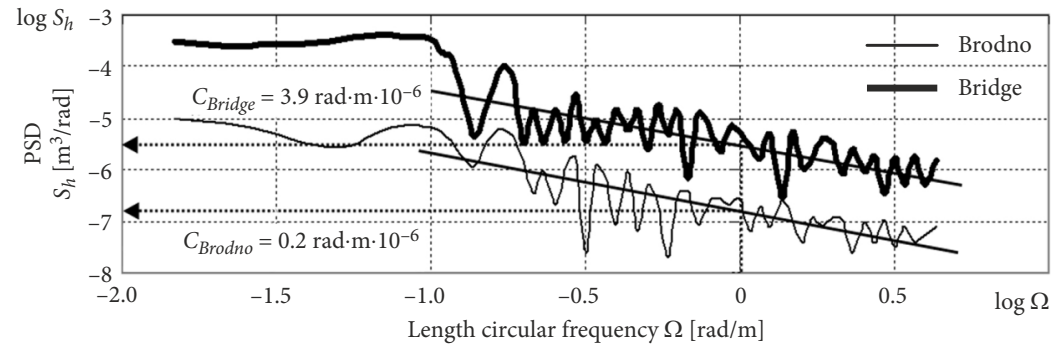

Figure 9. PSD of stochastic unevenness of road sections Brodno and Bridge

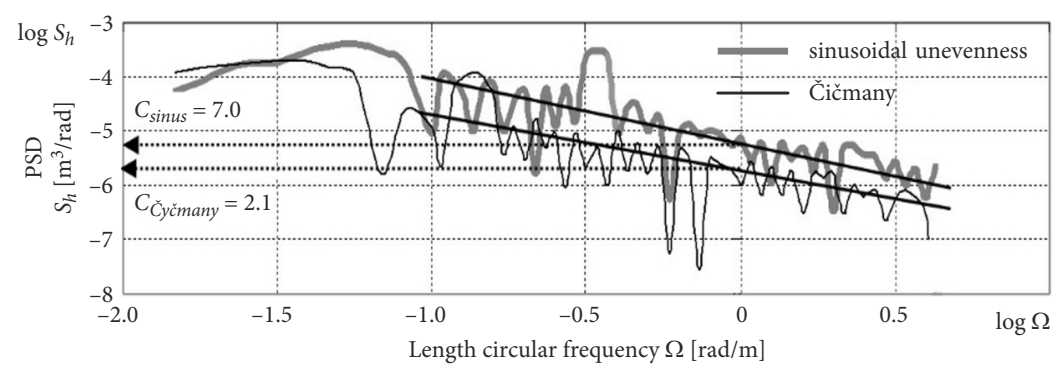

Figure 10. PSD of harmonic unevenness and stochastic unevenness of road section Čičmany

Table 1. The results of the longitudinal unevenness measurements of road section I/64

\begin{tabular}{|c|c|c|c|c|c|c|}
\hline \multirow{2}{*}{ Direction } & \multirow{2}{*}{ Ride number } & \multicolumn{2}{|c|}{ Measuring velocity } & \multirow{2}{*}{ Frequency $[\mathrm{Hz}]$} & \multicolumn{2}{|c|}{ Parameter $C\left[\mathrm{rad} \cdot \mathrm{m} \cdot 10^{-6}\right]$} \\
\hline & & {$[\mathrm{km} / \mathrm{h}]$} & {$[\mathrm{m} / \mathrm{s}]$} & & average & maximum \\
\hline \multirow[t]{6}{*}{ Bytča-Považská Bystrica } & 3 & 10 & 2.77 & 0.46 & 3.28 & 5.61 \\
\hline & 5 & 20 & 5.55 & 0.93 & 3.75 & 8.53 \\
\hline & 7 & 28 & 7.77 & 1.30 & 4.55 & 10.98 \\
\hline & 9 & 36 & 10.00 & 1.67 & 3.37 & 7.46 \\
\hline & 11 & 54 & 15.00 & 2.50 & 2.2 & 4.62 \\
\hline & 13 & 72 & 20.00 & 3.33 & 1.91 & 4.21 \\
\hline \multirow[t]{5}{*}{ Považská Bystrica-Bytča } & 6 & 20 & 5.55 & 0.93 & 3.46 & 6.78 \\
\hline & 8 & 28 & 7.77 & 1.30 & 3.92 & 7.55 \\
\hline & 10 & 36 & 10.00 & 1.67 & 3.07 & 6.74 \\
\hline & 12 & 54 & 15.00 & 2.50 & 1.84 & 4.26 \\
\hline & 14 & 72 & 20.00 & 3.33 & 1.76 & 3.72 \\
\hline
\end{tabular}



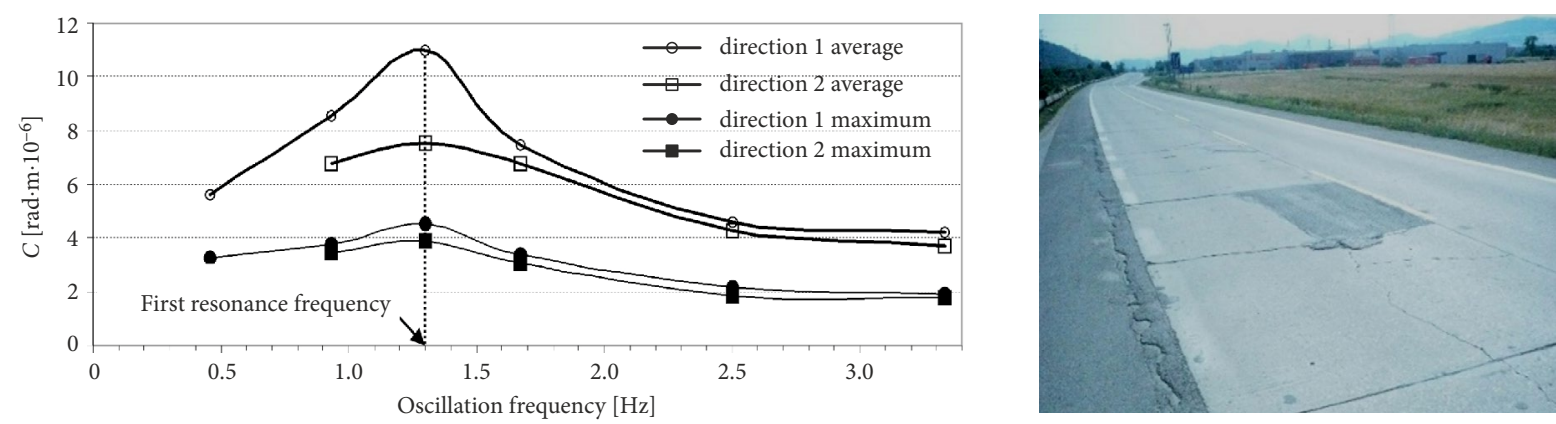

Figure 11. The dependence of parameter $C$ on oscillation frequency for concrete pavement (right side)

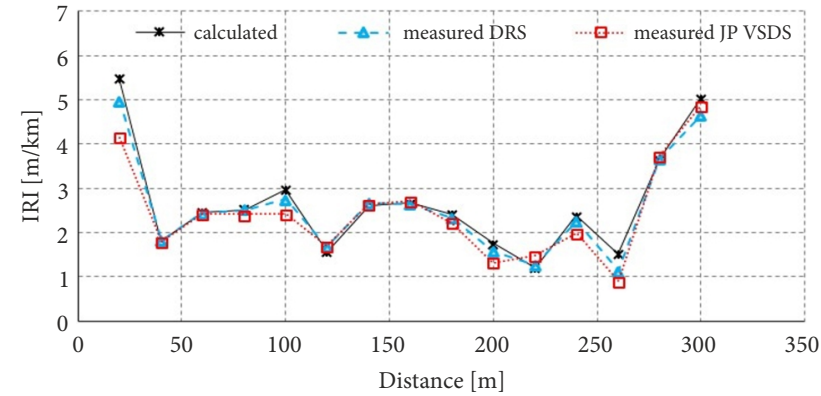

Figure 12. The comparison of calculated IRI values and IRI values measured by designed devices JP VSDS and DRS

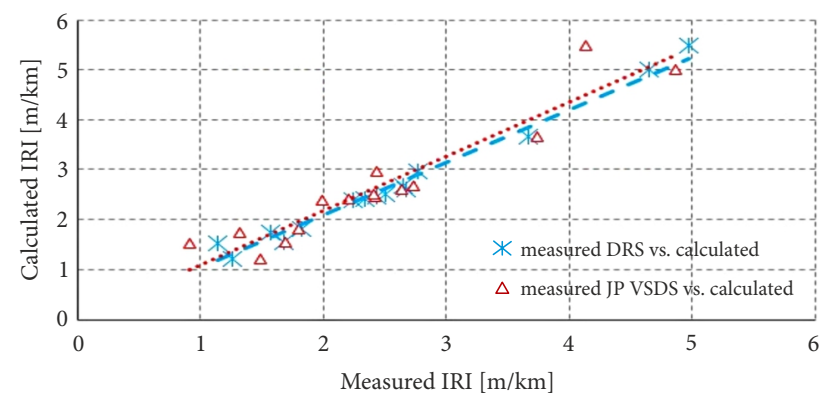

Figure 13. The correlation of calculated IRI values and IRI values measured by designed devices DRS and JP VSDS

There is a very good correlation between results of both devices and IRI values calculated by simulating program created according to presented models of quarter cars. However, presented results represent only few measurements on selected road sections and for absolute confirmation of correctness and reliability of designed devices it will be necessary to perform many further measurements, simulations and comparisons. Although, so far we can say that results are promising and perhaps designed devices will help to provide an objective input to the pavement management system with regard to ride safety and ride comfort.

The main advantage of UNIZA single-wheel vehicle JP VSDS is that it is a real quarter car, which allows to measure accelerations of sprung mass in real terms. The main advantage of DRS device is high resolution of scanning, which is very important for transversal unevenness (ruts) evaluation above all. In term off longitudinal unevenness evaluation is an added value a number of provided profiles for IRI parameter calculation. And also the opportunity to change parameters of quarter car model used for calculations of sprung/unsprung mass accelerations. Moreover, there is an effort to install an accelerometer on the wheel for the purpose of verification and a comparison of measured accelerations of the wheel and the car body and accelerations calculated using elevation data obtained by laser scanning

\section{Conclusions}

All experiences and knowledge obtained during over 15 years' research led to design of two original devices, which can be used for road pavement longitudinal unevenness evaluation. All calculations using mathematical models for simulation of quarter car movement so far confirmed correctness and the accuracy of the designed devices.

The UNIZA single-wheel vehicle JP VSDS has been designed for continuous high-speed survey. It can be used on any type of surface, paved or unpaved, and under severe environmental conditions. The results detected by the UNIZA single-wheel vehicle can be used for road unevenness evaluation and give an objective input for maintenance planning and for research on the impact of stochastic road unevenness on the vibrations and working loads of vehicles carrying elements.

The second device, the DRS designed in cooperation with company KVANT, also shows very good results so far, nevertheless there is still some areas for improving and debugging.

\section{Funding}

This work was supported by the European Regional Development Fund [projects ITMS 26220120050 - Centre of excellence for systems and services of intelligent transport II and ITMS 26220220183 - Research Centre of the University of Žilina] and the Scientific Grant Agency of Slovak Republic [projects VEGA 1/0159/19 - Assessment of the key elements resilience of the ground transport infrastructure and VEGA 1/0537/17 - The influence of pavement surface morphology on pavement serviceability and emissions production]. 


\section{References}

Cantisani, G.; Loprencipe, G. 2010. Road roughness and whole body vibration: evaluation tools and comfort limits, Journal of Transportation Engineering 136(9): 818-826. https://doi.org/10.1061/(ASCE)TE.1943-5436.0000143

Celko, J.; Decky, M.; Komacka, J.; Kovac, M. 2008. Pavement diagnosis as integrant of the pavement management system, Komunikácie: vedecké listy Žilinskej univerzity - Communications: Scientific Letters of the University of Žilina (2): 44-49.

Celko, J.; Decky, M.; Kovác, M. 2009. An analysis of vehicle-road surface interaction for classification of IRI in the frame of Slovak PMS, Eksploatacja i Niezawodność - Maintenance and Reliability (1): 15-21.

Chemistruck, H. M.; Detweiler, Z. R.; Ferris, J. B.; Reid. A. A.; Gorsich. D. J. 2009. Review of current developments in terrain, Proceedings SPIE 7348: 1-12. https://doi.org/10.1117/12.818128

Decký, M. 1999. Comparison of dynamic methods of road pavement evenness evaluation, Komunikácie: vedecké listy Žilinskej univerzity - Communications: Scientific Letters of the University of Žilina (2): 22-32.

Decký, M. 1996. Hodnotenie pozdĺžnych nerovností cestných vozoviek meracou sústavou VŠDS. Dizertačná práca. Žilinská univerzita v Žiline, Slovenská republika. 134 p. (in Slovak).

Decký, M.; Kováč, M. 2014. Pozdĺžna rovnost' vozoviek pozemných komunikácií. Edis. 222 s. (in Slovak).

Decký, M.; Leitner, B.; Kováč. M. 2004a. Klasifikácia rovnosti vozoviek zohladňujúca dynamiku reálneho automobilu. 1. čast', Silniční obzor 2: 49-54 (in Slovak).

Decký, M.; Leitner, B.; Kováč. M. 2004b. Klasifikácia rovnosti vozoviek zohladňujúca dynamiku reálneho automobile. 2. čast', Silniční obzor 3: 80-82 (in Slovak).

Delanne, Y.; Pereira, P.A.A. 2001. Advantages and limits of different road roughness profile signal-processing procedures applied in Europe, Transportation Research Record: Journal of the Transportation Research Board 1764: 254-259.

https://doi.org/10.3141/1764-26

EN 13036-5:2014. Road and Airfield Surface Characteristics. Test Methods. Part 5: Determination of Longitudinal Unevenness Indices.

Kotek, P.; Kovac, M.; Decky, M. 2015. The comparison of standard methods for pavement texture evaluation with unconventional approach using 3D scanning, SGEM2015 Conference Proceedings 1(2): 1167-1174. https://doi.org/10.5593/SGEM2015/B21/S10.149

Kropáč, O.; Múčka, P. 2009. Effects of longitudinal road waviness on vehicle vibration response, Vehicle System Dynamics: International Journal of Vehicle Mechanics and Mobility 47(2): 135-153. https://doi.org/10.1080/00423110701867299

Kropáč, O.; Múčka, P. 2006. Indicators of longitudinal unevenness of roads/runways, Czech Aerospace Proceedings (1): 34-45.

Mikolaj, J.; Remek, L.; Pepucha, L. 2014. Overview of the road network management system, Komunikácie: vedecké listy Žilinskej univerzity - Communications: Scientific Letters of the University of Žilina (4): 53-57.

Mikolaj, J.; Schlosser, F.; Remek, L. 2013. Life-cycle cost analysis in pavement management system, Komunikácie: vedecké listy Žilinskej univerzity - Communications: Scientific Letters of the University of Žilina (3): 102-106.
Múčka, P. 2015. Sensitivity of road unevenness indicators to distresses of composite pavements, International Journal of Pavement Research and Technology 8(2): 72-84. https://doi.org/10.6135/ijprt.org.tw/2015.8(2).72

Praticò, F. 2004. Nonstrictly-ergodic signals in road roughness analyses: a theoretical and experimental study, Proceedings of SIIV 2004 - II International Congress - New technologies and Modeling Tools for Roads - Applications to Design and Management, 27-29 October 2004, Florence, Italy.

Sayers, M. W. 1995. On the calculation of international roughness index from longitudinal road profile, Transportation Research Record 1501: 1-12.

Sayers, M. W.; Gillespie, T. D.; Queiroz. C. A. V. 1986. The International Road Roughness Experiment (IRRE): Eestablishing Correlation and a Calibration Standard for Measurements. World Bank Technical Paper No 45. Washington. DC, US. 468 p. Available from Internet: http://documents.worldbank. org/curated/en/326081468740204115

Wilde, W. J. 2007. Implementation of an International Roughness Index for Mn/DOT Pavement Construction and Rehabilitation. Report MN/RC-2007-09. Research Services Section. Minnesota Department of Transportation, Saint Paul, MN, US. 133 p. Available from Internet: http://dotapp7.dot.state.mn.us/research/pdf/200709.pdf

Willett, M.; Magnusson, G.; Ferne, B. W. 2000. Filter Experiment - Theoretical Study of Indices. FEHRL Technical Note 2000/02. Transport Research Laboratory. Crowthorne, Berkshire. UK. 51 p. 